\title{
Unequal Access to HIV Prevention Services by Gender in Benin
}

\author{
Mahouli Mireille-Marie Mintogbe ${ }^{1,2^{*}}$, Mouftaou Amadou Sanni' \\ Nelly Harmonie Bigbé Baké Ahoussinou ${ }^{2,3}$, Odile Sodolouffo ${ }^{4}$, Elihou Adje1, Djima Barano1 \\ ${ }^{1}$ Laboratory of Research in Population and Development Sciences (LaReSPD), Parakou, Benin \\ ${ }^{2}$ Institute of Communication Analysis and Social Assemblies (INACES), Porto-Novo, Benin \\ ${ }^{3}$ Faculty of Health Sciences of University of Abomey Calavi, Calavi, Benin \\ ${ }^{4}$ Plan International Benin, Cotonou, Benin \\ Email: *clema.mintogbe@gmail.com, mouftaouamadousanni@yahoo.fr
}

How to cite this paper: Mintogbe, M.M.-M., Sanni, M.A., Ahoussinou, N.H.B.B., Sodolouffo, O., Adje, E. and Barano, D. (2019) Unequal Access to HIV Prevention Services by Gender in Benin. Open Journal of Social Sciences, 7, 51-65.

https://doi.org/10.4236/jss.2019.76004

Received: April 10, 2019

Accepted: May 31, 2019

Published: June 3, 2019

Copyright (C) 2019 by author(s) and Scientific Research Publishing Inc. This work is licensed under the Creative Commons Attribution International License (CC BY 4.0).

http://creativecommons.org/licenses/by/4.0/

\section{Abstract}

HIV infection remains a serious issue of community intervention. In this context, many actions are developed and implemented by both public authorities and non-governmental organizations. These are interventions to prevent HIV transmission, overall care, etc. There is a problem of differential propensity according to gender and belonging to social categories access to prevent HIV services. This study aims to identify the explanatory factors for unequal access to HIV prevention services in Benin. Thus, data from the survey on gender-based violence related to HIV collected in 2017 by Plan International Benin were used. The sample size is 929; composed of vulnerable and key populations. Access to prevention services is a composite indicator based on four variables (screening, condom promotion, management of STIs, information, education and communication (IEC) and Communication for Behavioral Change (CBC)). The analysis is done using SPSS.21 software. The bi-varied association was performed using Pearson's Chi2 and Fisher's F tests and prediction of explanatory factors by logistic regression. In both 929 populations, 64.5\% (599) are key populations and 35.5\% (330) are vulnerable. In total, $22.5 \%$ (209) population did not have access to prevention services including $66.5 \%$ (139) of vulnerable people. Adolescents under 20 years of age (50.8\%), females (25.6\%), singles (27.2\%), farmers (61.1\%) and people living in rural areas $(43.4 \%)$ are more likely not to benefit from HIV prevention services. Five factors predict unequal access to prevent HIV interventions ( $p$ $<5 \%$ ). These are social status, marital status, education level, occupation and department of residence. Indeed, the: 1$)$ vulnerable people $(\mathrm{OR}=4.54), 2)$ divorced/widowed $(\mathrm{OR}=1.77), 3)$ uneducated $(\mathrm{OR}=1.61), 4)$ farmers $(\mathrm{OR}=$ 2.18) and 5) people living in the departments of Mono-Couffo $(\mathrm{OR}=2.57)$ 
have the highest odds ratio of poor access to HIV prevention services. From the above, it is necessary for the establishment of a mechanism to facilitate vulnerable people, especially women, access to HIV prevention services. In addition, there is a need to ensure global coverage of the availability and geographical accessibility of prevention services with particular attention in the department of Mono-Couffo.

\section{Keywords}

Gender, HIV Services, Key Populations

\section{Introduction}

In West and Central Africa (WCA), 6.1 million people are living with HIV, 370,000 are newly infected and more than 280,000 are dying from the disease mainly due to lack of access to prevention services, treatment and care for HIV infection [1]. Despite the progress made in the response to the disease in recent years through the implementation of the various strategies (combined prevention, screening and differentiated care, community screening, self-testing, test and treat, option $\mathrm{B}+$ etc.), the HIV pandemic remains one of the most serious threats to public health in many countries in sub-Saharan Africa. Beyond the consequences of the disease on individuals, it is families, communities and national economies that are paying the heaviest tribute to this pandemic. Recognizing the scale of this public health problem and the need to put in place urgent and adequate strategies, in September 2005, 191 United Nations member States adopted the goal of universal access: "to create an environment in which HIV prevention, treatment, care and support interventions are available, accessible and affordable for all who need them". This action strategy takes into account a wide range of interventions for individuals, families, communities and countries. In this context, preventive interventions include information and education, awareness raising, screening and management of sexually transmitted infections (STIs), HIV counseling and testing, promotion and distribution condoms [2] [3] [4]. There is also pre-exposure prophylaxis (PrEP) and post-exposure prophylaxis (PEP) in key populations that have been initiated recently but are in the pilot phase in several West African countries including Benin. According to UNAIDS, key populations include all those who are at higher risk of HIV transmission or who may be infected. Their mobilization and involvement are essential to the success of a response to the virus, in that they are essential for both the dynamics of the epidemic and the response.

Whatever the typology of the HIV epidemic, it is recommended by the World Health Organization (WHO) as part of the implementation of the universal access strategy, to give priority to accelerated prevention service through 1) the selection of prevention interventions that better match the modes of HIV transmission, 2) the identification and concentration of actions in geographical areas 
and subgroups of the population where the HIV prevalence is higher (key populations identified and retained by country), and 3) selection of HIV counseling and testing methods that optimize entry to prevention, treatment and care [2]. Indeed, the purpose of these services in the prevention of HIV infection is to help reduce the risk of infection. They are one of the arsenals for reducing new infections.

According to the 4th Edition of the Demographic and Health Survey of Benin (EDSB-IV), the prevalence of HIV in the general population is $1.2 \%$ [5] and at least twice as high in key populations groups: Sex workers: 8.5\% [6], Men who have sexual relations with Men (MSM): $7.7 \%$ and Injecting Drug Consumers (IDC): $2.2 \%$ [7]. The main mode of transmission of the virus is the sexual way through unprotected sex. In fact, according to the 2017 EDSB-V, $13.0 \%$ of women and $31.0 \%$ of men have had risky sexual relations. Of these, only $22.0 \%$ of women and $32.0 \%$ of men used condoms during unsafe sex. In addition, with regard to knowledge of HIV status, only $35.0 \%$ of women and $18.0 \%$ of men have been tested for HIV in the 12 months preceding the survey. Of these, 14.0\% of women and $7.0 \%$ of men received the results of this last screening HIV test [8].

In accordance with WHO guidelines, Benin set up prevention and treatment interventions with progressive extension throughout the country following the discovery of the AIDS disease in 1985. These interventions include services such as: 1) Information, Education and Communication (IEC), 2) Communication for a Change of Behaviours (CBC), 3) Sexually Transmitted Infections (STI) management, 4) promotion and awareness of the correct and consistent use of condoms, 5) HIV testing, 6) HIV care and treatment, 7) screening and pre-and post-exposure prophylaxis among key population groups. However, Gender-Based Violence (GBV), stigma and discrimination represent major obstacles to universal access to HIV prevention and treatment programs.

Gender is culturally defined as a set of roles, responsibilities, economic, social and political rights and obligations associated with being a woman or a man. It refers to power relations between and among women and men, boys and girls. Thus, the status of the individual according to gender varies from one culture to another, from one geographical area to another, from one era to another and according to the sub-categories that make up the general population (vulnerable people, key populations, etc.). In such a context, anyone whose gender identity does not conform to the norms and expectations traditionally associated with their genital sex assigned at birth are otherwise perceived in their community. Such a climate makes them victims of many ills (violence, discrimination, stigmatization, harassment, social exclusion, etc.). For example, among the groups of key populations trans-sexual is distinguished; these are people who, while physically belonging to one sex, have the feeling of belonging to another; they often try to access a more coherent and less equivocal identity by submitting to medical care and surgical interventions in order to adapt their physical characteristics to their psychic character. These key populations by their gender identity 
are particularly overexposed to contaminations, especially through HIV and face specific health problems. For example, HIV prevalence is $7.7 \%$ among MSM while it is below $2 \%$ in the general population [7].

The gender-based violence (GBV) is a violence that finds these roots in gender inequalities and refers to the abuse of power of a person because of his gender identity and expectations of his role in a society or in a culture. In African societies, GBV is one of the determinants of the spread of HIV, particularly in the subpopulations of girls/women and key populations. As an illustration, in Benin, the results of the study on the extent and types of violence suffered during childhood in trans-sexual persons, shows that verbal abuse is the most frequent (90.0\%). They are followed by physical violence (56.9\%) and sexual violence: $5.9 \%$ [9].

Indeed, patriarchal socio-cultural norms based on gender tend to reinforce power inequalities, discrimination and stigmatization towards certain men, women, adolescents and other gender identities and limit their abilities and opportunities to make appropriate decisions or to adopt healthy and positive health behaviors against HIV such as access to HIV prevention services. Another major factor that reinforces gender inequalities in key populations is the public's awareness of sexual orientation, the status of targets, or their behavior outside of societal norms.

These inequities not only drive key populations and the most vulnerable people, victims to underestimate themselves, but also reduce their access to HIV health services. To this situation of gender inequality are added demographic factors (age, sex, education level, etc.), socio-cultural factors (place of residence, religion, etc.) and economic factors (social class, occupation, etc.) that influence the access to HIV services as demonstrated by previous studies conducted on the issue and compiled through a meta-analysis by Kaufman et al. [10].

From above, this paper raises the issue of the explanatory factors of unequal access to HIV prevention services in the Beninese context.

\section{Methodology}

\subsection{Data}

This study is based on data collected in 2017 by Plan International Benin. They were collected as part of the investigation into gender-based violence related to HIV. The sampling takes into account the urban, the rural erea and also the twelve departments of the country. The data collected relate to: 1) the risks of gender-based violence and its consequences, 2) the institutional and legal framework, the constraints related to equitable access to HIV prevention, care and treatment services; 3) the potential social, behavioral, environmental, organizational and other factors of stigmatization and discrimination associated with gender-based violence specific to women, girls, and key populations [7]. The key and vulnerable populations in the number of 929 involved in the study are: women (18\%, $\mathrm{N}=169)$, girls aged 10 to $15(7.1 \%, \mathrm{~N}=66)$, Sex workers $(21.2 \%$, 
$\mathrm{N}=197)$, Men who have sexual relations with Men (10.7\%, $N=99)$, Injecting Drug Consumers (8.1\%, $\mathrm{N}=75)$, Living People with HIV (16.9\%, $\mathrm{N}=157)$, Lesbians $(4.7 \%, \mathrm{~N}=44)$ and transgender people $(2.9 \%, \mathrm{~N}=27)$.

The data collected made it possible to assess the accessibility of the various prevention services except PrEP and PEP, which are in the experimental phase. The dependent variable is a composite variable calculated from four variables (information, education and communication: IEC/Communication for Behavioral Change: $C B C$, HIV testing, STI management, and condom promotion). A person who claims to have benefited from at least one of the four services has been considered to have accessed HIV prevention services. The variable to be explained is a binary variable with two (02) modalities: "benefited" and "did not benefit".

The explanatory variables were recorded in two categories: socio-demographic characteristics (age, sex, education level, marital status, place of residence, department of residence and nationality) and economic characteristics (occupation). The choice of these explanatory variables is essentially based on the literature review and the possibilities offered by the database.

\subsection{Methods}

The data analysis is descriptive, bi-varied and multivariate from a logistic regression for the explanatory factors search. The search for associations between the studied phenomenon and the explanatory variables was carried out on the basis of the Pearson Chi2 and F Fischer association measurement tests. Moreover, in addition to the association tests, the collinearity conditions were verified by measuring the gross effects before the actual logistic regression into three models: a model on all two categories of population studies and two other models on each type of population. A threshold of significance of $5 \%$ is retained.

The multivariate logistic regression model is as follows:

$$
\ln \left(\frac{p}{1-P}\right)=\operatorname{logit}(p)=\beta_{0}+\beta_{1} * X_{1}+\beta_{2} * X_{2}+\beta_{i} * X_{i}+\varepsilon
$$

$\operatorname{logit}(p)=$ probability of unequal access to prevention services;

$X_{i}=$ Set of explanatory variables (with $i$ ranging from 1 to $\mathrm{n}$ );

$\beta_{i}=$ coefficients $\beta$ respectively attached to each explanatory factor;

$\varepsilon=$ error term.

\section{Results}

\subsection{Description of the Sample}

The socio-demographic and economic characteristics of the sample are presented in (Table 1$)$. The median age is 29 years $( \pm 0.37)$ ranging between 10 and 65 years old with variations according to the type of population. In the vulnerable group, the mean age is 28 years $( \pm 0.78)$ and 30 years $( \pm 0.30)$ among key populations. The youngest of the vulnerable at age 10 while among the youngest key populations is 15 years old and the oldest 65 years old. 
Table 1. Description of the sample.

\begin{tabular}{|c|c|c|c|c|c|c|}
\hline \multirow{2}{*}{ Variables } & \multicolumn{2}{|c|}{ All population } & \multicolumn{2}{|c|}{ Vulnerable People } & \multicolumn{2}{|c|}{ Key Population } \\
\hline & $\%$ & $\mathbf{n}$ & $\%$ & $\mathbf{N}$ & $\%$ & $\mathbf{n}$ \\
\hline \multicolumn{7}{|l|}{ Age group } \\
\hline $10-19$ & $14.0(11.9-16.3)$ & 130 & $30.9(26.0-36.0)$ & 102 & $4.7(3.1-6.6)$ & 28 \\
\hline $20-24$ & $16.7(14.2-19.2)$ & 155 & $8.8(5.8-12.0)$ & 29 & $21.0(17.7-24.1)$ & 126 \\
\hline $25 \&$ plus & $69.3(66.4-72.2)$ & 644 & $60.3(54.7-65.3)$ & 199 & $74.3(71.1-77.7)$ & 445 \\
\hline \multicolumn{7}{|l|}{ Sex } \\
\hline Male & $34.9(31.8-38.1)$ & 324 & $29.4(24.2-34.4)$ & 97 & $37.9(34.0-41.8)$ & 227 \\
\hline Female & $65.1(61.9-68.2)$ & 605 & $70.6(65.6-75.8)$ & 233 & $62.1(58.2-66.0)$ & 372 \\
\hline \multicolumn{7}{|l|}{ Nationality } \\
\hline Beninese & $85.6(83.3-87.7)$ & 795 & $97.9(96.3-99.4)$ & 323 & $78.8(75.5-81.7)$ & 472 \\
\hline Other & $14.4(12.3-16.7)$ & 134 & $2.1(0.6-3.7)$ & 7 & $21.2(18.3-24.5)$ & 127 \\
\hline \multicolumn{7}{|l|}{ Marital status } \\
\hline In union & $40.0(37.0-43.3)$ & 372 & $49.4(43.9-54.8)$ & 163 & $34.9(31.1-38.8)$ & 209 \\
\hline Single & $42.3(39.2-45.5)$ & 393 & $37.0(31.8-42.3)$ & 122 & $45.2(41.2-49.2)$ & 271 \\
\hline Divorced/widowed & $17.7(15.3-20.3)$ & 164 & $13.6(9.8-17.6)$ & 45 & $19.9(16.8-23.1)$ & 119 \\
\hline \multicolumn{7}{|l|}{ Education level } \\
\hline Not in school & $20.0(17.7-22.6)$ & 186 & $20.6(16.4-24.8)$ & 88 & $19.7(16.4-23.1)$ & 118 \\
\hline Primary & $28.2(25.4-31.3)$ & 262 & $29.7(24.8-34.9)$ & 98 & $27.4(24.0-31.3)$ & 164 \\
\hline Secondary & $43.4(40.4-46.5)$ & 403 & $41.5(36.4-47.1)$ & 137 & $44.4(40.1-48.6)$ & 266 \\
\hline University & $8.4(6.7-10.2)$ & 78 & $8.2(5.4-11.1)$ & 27 & $8.5(6.3-10.9)$ & 51 \\
\hline \multicolumn{7}{|l|}{ Occupation } \\
\hline Unemployed & $25.7(23.0-28.6)$ & 239 & $9.1(6.0-12.2)$ & 30 & $34.9(31.1-38.8)$ & 209 \\
\hline Craftsman/artist & $28.0(25.3-31.0)$ & 260 & $29.1(24.3-33.9)$ & 96 & $27.4(23.6-31.0)$ & 164 \\
\hline Housewife & $10.8(8.8-12.6)$ & 100 & $7.9(5.2-10.8)$ & 26 & $12.4(9.7-15.0)$ & 74 \\
\hline Farmers & $7.8(6.1-9.6)$ & 72 & $17.9(14.0-22.2)$ & 59 & $2.2(1.0-3.5)$ & 13 \\
\hline Traders & $17.2(15.0-19.7)$ & 160 & $26.4(21.6-31.1)$ & 87 & $12.2(9.6-14.7)$ & 73 \\
\hline Official & $10.5(8.6-12.5)$ & 98 & $9.7(6.7-12.9)$ & 32 & $11.0(8.6-13.5)$ & 66 \\
\hline \multicolumn{7}{|l|}{ Residence erea } \\
\hline Urban & $91.8(90.0-93.5)$ & 853 & $77.0(72.4-81.4)$ & 254 & $100-$ & 599 \\
\hline Rural & $8.2(6.5-10.0)$ & 76 & $23.0(18.6-27.6)$ & 76 & $00-$ & 00 \\
\hline \multicolumn{7}{|l|}{ Departments } \\
\hline Alibori-Borgou & $10.7(8.7-12.6)$ & 99 & $13.3(9.9-16.9)$ & 44 & $9.2(7.0-11.6)$ & 55 \\
\hline Atacora-Donga & $5.9(4.4-7.5)$ & 55 & $7.3(4.7-10.2)$ & 24 & $5.2(3.4-7.2)$ & 31 \\
\hline Oueme-Plateau & $11.29 .0-13.3)$ & 104 & $7.3(4.5-10.3)$ & 24 & $13.4(10.7-16.2)$ & 80 \\
\hline Zou-Couffo & $11.2(9.0-13.2)$ & 104 & $17.6(13.8-21.4)$ & 58 & $7.7(5.6-9.8)$ & 46 \\
\hline Mono-Couffo & $7.2(5.8-8.9)$ & 67 & $17.3(13.3-21.4$ & 57 & $1.7(5.6-9.8)$ & 10 \\
\hline Atlantique-Litoral & $53.8(50.5-56.9)$ & 500 & $37.3(32.3-42.8)$ & 123 & $62.9(58.8-67.0)$ & 377 \\
\hline Total & 100.0 & 929 & 35.5 & 330 & 64.5 & 599 \\
\hline
\end{tabular}


Among vulnerable people, women are $70.6 \%$ while the group of key populations has $62.1 \%$ of female claimants. More than three quarters (77.0\%) of vulnerable people come from urban areas, while all key populations live in urban areas because urban areas are those with high concentration of this subpopulation.

According to education level, high school students are the most represented: $41.5 \%$ of vulnerable people and $44.4 \%$ of keys. Regarding marital status, about $49.4 \%$ of vulnerable people live in unions while $45.2 \%$ of key populations are single. The occupation reveals that $29.1 \%$ of vulnerable people are engaged in crafts and $34.9 \%$ of key populations are unemployed (unemployed or still students, or apprentices at the time of the survey). In addition, foreign nationals are more important among key populations than among vulnerable people $(21.2 \%$ vs $2.1 \%)$.

\subsection{Classification According to the Degree of Inequality in Access to Prevention Services}

Among the subjects who benefited from prevention services during the reference period, a classification according to the degree of accessibility allows a hierarchy at four levels: 1) weak access: when a person has benefited from a single service; 2) average access: when a person has benefited from two services; 3 ) high access: when one person has received three services and 4) very high access: when a person has benefited from the four prevention services during the reference period.

A total of $720(77.5 \%)$ subjects had access to prevention services in the 12 months preceding data collection. Of these, seven in ten $(73.5 \%, \mathrm{n}=529)$ are key populations, compared to only one in four of the vulnerable people $(26.5 \%, \mathrm{n}=$ $191, p<0.001)$. The distribution of the degree of access according to the classification presented above on the whole of the two groups of populations on the one hand; and on the other hand, by type of population is shown in Figure 1. Regardless of the level of classification, vulnerable populations have less access when

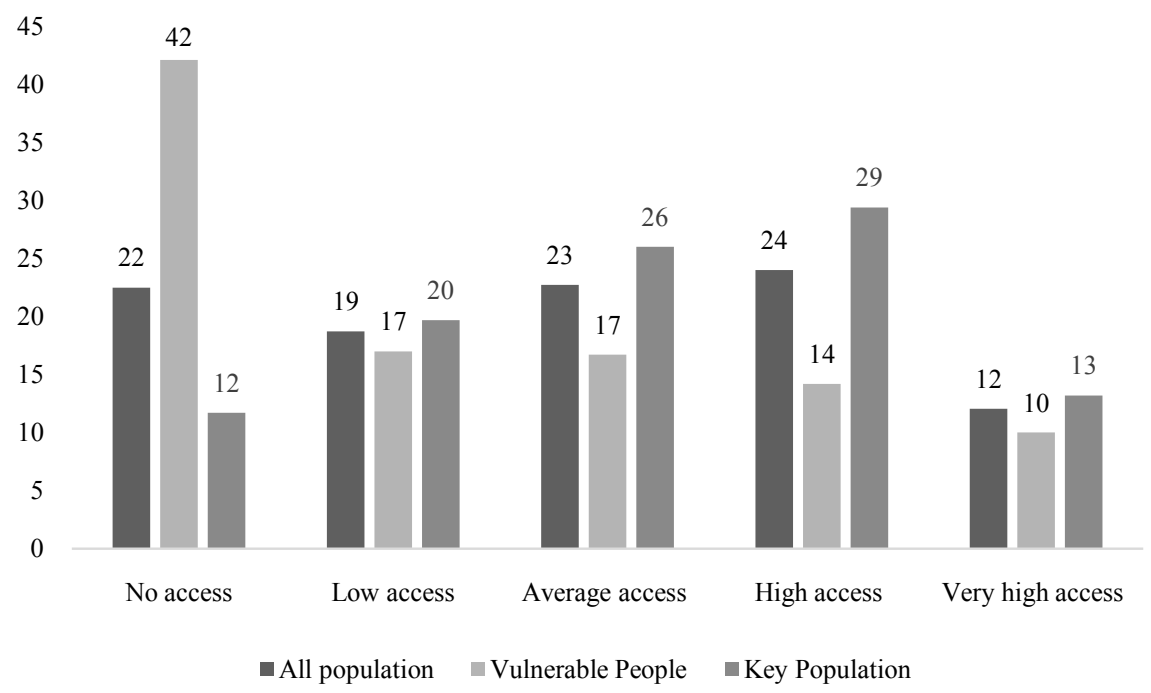

Figure 1. Distribution of population types by degree of access to prevention services. 
reaching the highest level of access. In the latter subgroup, $17 \%$ have access to at least two types of prevention services compared to $26 \%$ in the key population group. After this maximum, only $10 \%$ benefited from the four preventive services considered against $13 \%$ among key populations $(p<0.001)$.

\subsection{Unequal Access to HIV Prevention Services and Associated Factors}

Overall, 22.5\% (209) of the study population report that they did not have access to at least one of the four HIV prevention services considered in the twelve months preceding the survey. Of these, six in ten $(66.5 \%, \mathrm{n}=139)$ are vulnerable, compared to only three out of ten among key populations $(33.5 \%, \mathrm{n}=70)(p$ $<0.001$ ).

Following the order of importance among the subgroups of populations who did not have access to prevention services over the observation period, women (51.7\%), followed by men (14.8\%) and Sex workers (10.5\%) are mainly those with limited access to HIV prevention services (Figure 2).

Not access to HIV prevention services is associated with age, sex, marital status, education level, occupation, and areas of residence (Table 2). In fact, adolescents under $20(57.8 \%, p=0.001)$, females $(46.4 \%, p=0.011)$, singles $(52.5 \%$, $p=0.014)$, uneducated people $(52.9 \%, p=0.001)$, farmers, housewives $(72.9 \%$ and $65.4 \%, p<0.001)$ and people living in the departments of Oueme-Plateau $(91.7 \%)$ and Mono-Couffo $(65.4 \%)(p<0.001)$ are those who are more likely to not benefit from prevention services among vulnerable people.

As for the category of key populations, it appears that the same variables as those mentioned above, except gender and education level, are associated with the low accessibility to HIV prevention services (Table 2). Teenagers under 20

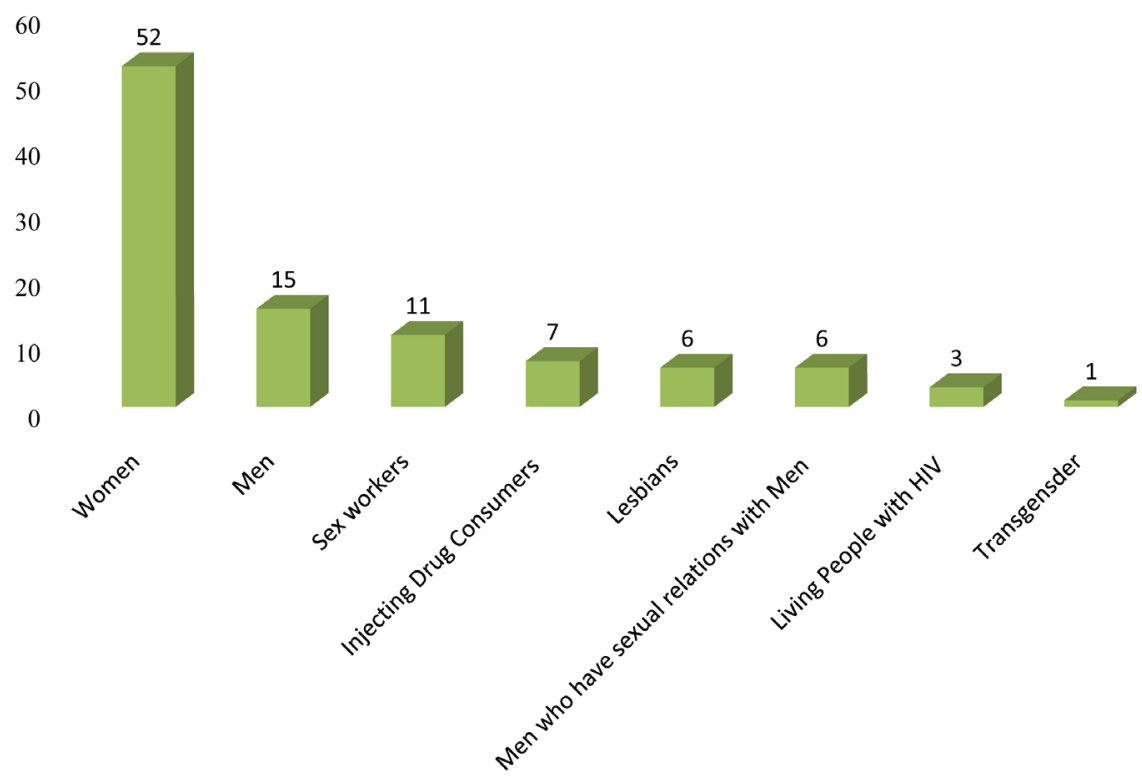

Figure 2. Proportion of people with low access to prevention services by type of population. 
Table 2. Non-access to HIV prevention services by socio-demographic and economic variables.

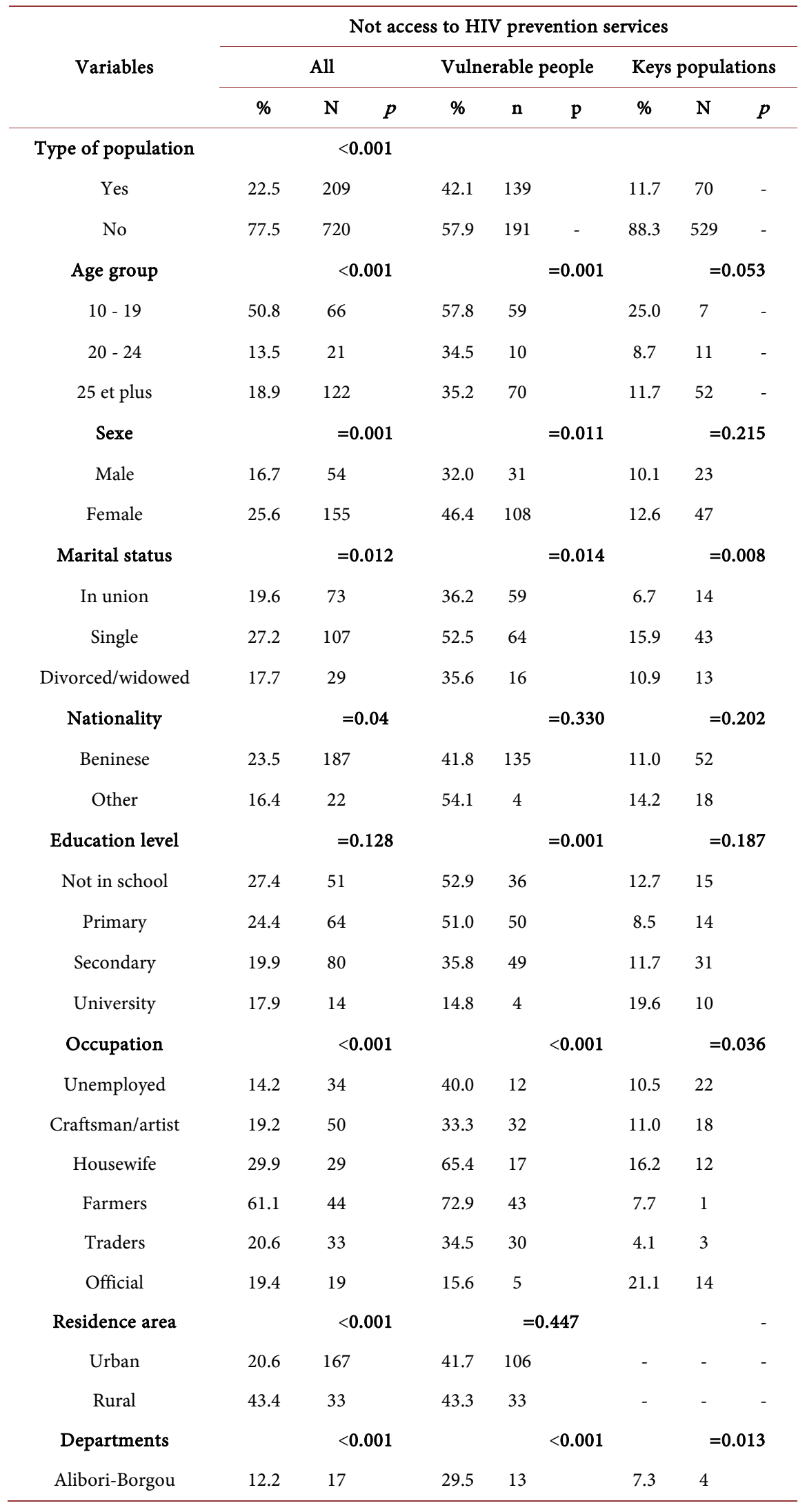


Continued

\begin{tabular}{ccccccc}
\hline Atacora-Donga & 16.4 & 9 & 37.5 & 9 & 0.0 & 0 \\
Atlantique-Littoral & 18.2 & 91 & 27.6 & 34 & 15.1 & 57 \\
Mono-Couffo & 56.7 & 38 & 64.9 & 37 & 10.0 & 1 \\
Oueme-Plateau & 24.0 & 25 & 91.7 & 22 & 3.8 & 3 \\
Zou-Collines & 27.9 & 29 & 41.4 & 24 & 10.9 & 5 \\
Total & $\mathbf{2 2 . 5}$ & $\mathbf{2 0 9}$ & $\mathbf{6 6 . 5}$ & $\mathbf{1 3 9}$ & $\mathbf{3 3 . 5}$ & $\mathbf{7 0}$ \\
\hline
\end{tabular}

years old $(25.0 \%, p=0.053)$, singles $(15.9 \%, p=0.008)$, public officials, farmers $(21.1 \%$ and $16.2 \%, p=0.036)$ and residents of the Atlantic and Littoral departments $(15.1 \%, p=0.013)$ are the most discriminated against in the accessibility of HIV prevention services.

\subsection{Explanatory Factors of Unequal Access to HIV Prevention Services}

Model 1 (Table 3) shows that factors such as: type of population, age, marital status, nationality, education, occupation, and areas of residence explain unequal access to prevention services. Thus, compared to key populations, vulnerable people have 4.5 times $(p<0.001)$ more risk of not receiving services to prevent HIV infection.

According to model 2, compared to public officials, housewives run 6.49 times $(p<0.001)$ more risk of not accessing prevention services while this risk is 4.99 times $(p<0.05)$ for farmers. As for the departments of residence, those living in the departments of Ouémé-Plateau have 26.04 times $(p<0.001)$ more risk of not to benefit HIV prevention services compared to their counterparts in the Atlantic-Littoral departments. This risk is respectively 5.58 and 2.32 times $(p<0.05)$ for the residents of the departments of Mono-Couffo and Zou-Collines.

As for model 3, four variables are associated with the low accessibility of prevention services in key populations. In fact, compared to adults aged 25 and over, young people aged $20-24$ are 0.37 times less likely $(p<0.05)$ not to access prevention services. Relative to those in a union, single people were 0.37 times less likely $(p<0.05)$ to miss out on HIV prevention services. Unemployed persons and traders were 0.49 times $(p<0.05)$ and 0.16 times $(p<0.001)$ less likely to have access to prevention services compared to public servants. In addition, residents of the departments of Borgou-Alibori and Ouémé-Plateau were 0.37 times $(p<0.05)$ and 0.16 times $(p<0.001)$ less risky than those in the departments of Atlantique-Littoral not to benefit from services to prevent HIV infection.

\section{Discussion}

The results of this study show that key populations are more likely to benefit from HIV prevention services compared to vulnerable people. This finding is not consistent with literature data that highlights the hidden nature of key populations 
Table 3. Models of drivers of inequalities in access to HIV prevention services between key populations and vulnerable people (Odds Ratios).

\begin{tabular}{|c|c|c|c|}
\hline \multirow{2}{*}{ Variables } & Model 1 & Model 2 & Model 3 \\
\hline & Odds Ratios & Odds Ratios & Odds Ratios \\
\hline --2Log likelihood & 800.536 & 354.182 & 381.428 \\
\hline Nickname R-two & 0.381 & 0.337 & 0.20 \\
\hline \multicolumn{4}{|l|}{ Type of population } \\
\hline Vulnerables people & $4.54^{* * *}$ & - & - \\
\hline Key population & Ref & - & - \\
\hline \multicolumn{4}{|l|}{ Age group } \\
\hline $10-19$ & 1.45 & 2.04 & 1.48 \\
\hline $20-24$ & $0.58^{* *}$ & 0.88 & $0.37^{* *}$ \\
\hline 25 and plus & Ref & Ref & Ref \\
\hline \multicolumn{4}{|l|}{ Sex } \\
\hline Female & 1.34 & 1.42 & - \\
\hline Male & Ref & Ref & - \\
\hline \multicolumn{4}{|l|}{ Marital status } \\
\hline Single & 0.94 & 1.39 & $0.37^{\star *}$ \\
\hline Divorced/widowed & $1.77^{\star *}$ & 2.06 & 1.30 \\
\hline In union & Ref & Ref & Ref \\
\hline \multicolumn{4}{|l|}{ Nationality } \\
\hline Benenese & $0.56^{* *}$ & - & - \\
\hline Other & Ref & - & - \\
\hline \multicolumn{4}{|l|}{ Education level } \\
\hline Not schooling & $1.61^{* *}$ & 1.44 & - \\
\hline Literate & Ref & Ref & - \\
\hline \multicolumn{4}{|l|}{ Occupation } \\
\hline Unemployed & 0.62 & 1.80 & $0.49^{* *}$ \\
\hline Craftsman/artist & 0.74 & 1.88 & 0.65 \\
\hline Housewife & 1.60 & $6.49^{* * *}$ & 0.81 \\
\hline Farmers & $2.18^{* *}$ & $4.99^{* *}$ & 1.03 \\
\hline Traders & 0.58 & 2.32 & $0.16^{* * *}$ \\
\hline Official & Ref & Ref & Ref \\
\hline \multicolumn{4}{|l|}{ Residence area } \\
\hline Urban & 0.93 & - & - \\
\hline Rural & Ref & - & - \\
\hline \multicolumn{4}{|l|}{ Departments } \\
\hline Alibori-Borgou & 0.70 & 1.28 & $0.37^{\star *}$ \\
\hline Atacora-Donga & $0.42^{\star *}$ & 1.19 & 0.00 \\
\hline
\end{tabular}


Continued

\begin{tabular}{cccc}
\hline Oueme-Plateau & 1.14 & $26.04^{* * *}$ & $0.16^{* * *}$ \\
Zou-Couffo & 1.17 & $2.32^{* *}$ & 0.71 \\
Mono-Couffo & $2.57^{* * *}$ & $5.58^{* * *}$ & 0.32 \\
Atlantique-Litoral & Ref & Ref & Ref \\
\hline
\end{tabular}

${ }^{* * *} p<1 \%,{ }^{* *} p<5 \%$, Ref $=$ Terms of reference.

as a result of criminalization and stigmatization of same-sex relationships, poorly perceived sex work, drug use, sexual and gender-based violence and discrimination. The factors raised explain the low accessibility of key populations to HIV services [11] [12] [13] [14]. Since 2015, Benin has opted for a new direction in the response to the HIV epidemic. This emphasizes interventions directed at key populations, drivers of the epidemic. Thus, it is noted the development of new strategies based on the mobile and community approach by bringing HIV services closer to key populations without maintenance of learning in the direction of other subpopulations [15].

The search for explanatory factors reveals that age is an important factor in the low accessibility of HIV prevention services and its positive effect is greater after the age of 24 . This result could be explained by the fact that prevention interventions target adults more often than adolescents and young people. Socio-cultural burdens are at the origin of the poor accessibility of health services in general and of reproductive health, particularly by adolescents and young people. This results from the fact that the language used by these services is not adapted to this specific group, which explains the high rate of use of educational centers for young people, the use of social networks and green lines for young people mainly exploited by adolescents and young people [1] [16].

In Malawi, this has been done as part of the assessment of the effect of preventive interventions to reduce the risk of HIV infection among adolescents under 20 years of age. The results of the study show a negative effect between interventions and the risk of infection because interventions are poorly adapted to beneficiaries [17].

However, outside of age, marital status, occupation and the areas of residence are also factors that predict accessibility. According to Gourlay et al. [18] in Tanzania and Nsom Mbo in 2007 in Cameroon [19], it is vulnerable people living in urban areas who are more likely to access HIV services. In Uganda according to [20] in 2015, people who live in cities have 2.5 times $(p<0.05)$ more access to HIV services than those living in rural areas. Contrary to the results observed by these authors, the present study shows that Atlantic-Littoral departments more urbanized and having more than $30 \%$ of HIV services despite that they account for a quarter $(24.8 \%)$ of the population of the countries offer few HIV interventions to the vulnerable population. Indeed, it is the key populations that are more concentrated (headquarters networks, structures, groups and associations) who benefit more from HIV prevention services. This follows from 
the Accelerated National HIV Response Acceleration Action Plans that focus on interventions targeting key populations in the country's major urban centers (Cotonou, Porto-Novo, Bohicon, Dogbo, Abomey and Djougou) to reach the 90-90-90 target in 2020 [15].

The influence of occupation on accessibility cannot be surprising. Indeed, some studies have shown that the type of occupation according to the exercise environment conditions access to prevention services. Economic activity allows the individual to have the resources to cover his or her health needs. Even if prevention services are normally free, there are and still indirect costs or costs related to geographical accessibility that limit access to the poorest. As a result, farmers in rural areas as well as housewives with low purchasing power, will be limited to access because of these constraints. By way of illustration, [19] shows in Cameroon that compared to farmers, persons with a profession in the craft sector and civil officials were respectively 1.47 times and 2.32 times $(p<0.05)$ more access to prevention services, in particular screening services.

\section{Conclusions}

The purpose of this study is twofold in the way to show that there is inequality in access to HIV prevention services by gender and social status, and to investigate the factors behind this situation.

The results show that there is indeed inequality in access to HIV prevention interventions according to the degree of vulnerability and risk.

Teenagers and women who are particularly vulnerable to HIV have very little access to prevention services. The main factors explaining these differences for the entire population under study are occupations and the areas of residence. To these two factors are added age and marital status in the group of key populations.

These results suggest the establishment of a system that can enable vulnerable people in general and women in particular who are most at risk of HIV to access prevention services. Also, it is essential to take steps to ensure geographical accessibility and permanent availability of HIV prevention services in all departments of Benin, particularly those of Ouémé-Plateau and Mono-Couffo.

\section{Acknowledgements}

Authors are grateful to the Plan Internationnal Benin which provided database used.

\section{Conflicts of Interest}

Authors declared that there is no conflict of interest concerning this manuscript.

\section{References}

[1] ONUSIDA (2018) Unaids, Data 2018. Rapport synthèse. UNAIDS, Geneva.

[2] WHO (2009) Interventions prioritaires: Prévention, traitement et soins du VIH/SIDA 
dans le secteur de la santé. Version 1.2 Rapport, 165.

[3] ONUSIDA (2015) Accélérer la prévention combinée afin de réduire les nouvelles infections par le VIH à moins de 500000 d'ici à 2020. Rapport référence ONUSIDA/JC2766F.

[4] ONUSIDA (2008) Vers un accès universel: Étendre les interventions prioritaires liées au VIH/Sida dans le secteur de la santé. Extraits du rapport de situation 2008, 13.

[5] INSAE (2012) Enquête Démographique et de Santé (Rapport définitif). Bénin: Institut National de la Statistique et de l'Analyse Économique (INSAE) [Bénin] et Macro International Inc., 573.

[6] PSLS-Bénin (2017) Rapport de Monitoring des activités de l'année 2016. Cotonou, Bénin.

[7] Plan International Benin (2017) Etude sur les violences basées sur le genre en lien avec le VIH et la stigmatisation/Discrimination. Rapport Final. Cotonou, Bénin.

[8] INSAE (2018) Enquête Démographique et de Santé (Rapport provisoire). Bénin: Institut National de la Statistique et de l'Analyse Économique (INSAE) [Bénin] et Macro International Inc., 74.

[9] Plan International Bénin (2017) Analyse de la situation des personnes transgenres en matière de l'infection à VIH et le sida au BENIN. Rapport Final, Décembre 2017.

[10] Kaufman, R.M., Cornish, F., Zimmerman, S.R. and Johnson, B.T. (2014) Health Behavior Change Models for HIV Prevention and AIDS Care: Practical Recommendations for a Multi-Level Approach. Journal of Acquired Immune Deficiency Syndromes, 66, 250-258.

[11] Lo, Y.-R., Christine, S., Soro, B.N. and Kariburyo, J.M. (2008) Prévention et prise en charge de l'infection du VIH/SIDA et des autres IST ciblant les professionnels du sexe et leurs partenaires en Côte d'Ivoire: rapport de la mission technique d'appui OMS, 38.

[12] Sears, B. and Mallory, C. (2011) Documented Evidence of Employment Discrimination and Its Effects on LGBT People. The Williams Institute, Los Angeles, CA, 20.

[13] Geoffroy, M. and Chamberland, L. (2015) Discrimination des minorités sexuelles et de genre au travail: quelles implications pour la santé mentale? Santé mentale au Québec, 40, 145-172. https://doi.org/10.7202/1034916ar

[14] WHO (2016) Lignes directrices unifiées sur la prévention, le diagnostic, le traitement et les soins du VIH pour les populations clés. Bureau régional de l'OMS pour l'Afrique, 180.

[15] CNLS-Bénin (2017) Rapport de suivi de la déclaration de politiques au Bénin: GAM 2016, 55.

[16] Amadou Sanni, M. and Attemba, R. (2011) Santé de la reproduction des adolescents: Défis des Réformes des Systèmes de Santé. Bulletin d Information sur la Population en Afrique et à Madagascar, 52, 1-10.

[17] Mwale, M. and Muula, A.S. (2018) Effects of Adolescent Exposure to Behaviour Change Interventions on Their HIV Risk Reduction in Northern Malawi: A Situation Analysis. SAHARA J: Journal of Social Aspects of HIVIAIDS, 15, 146-154. https://doi.org/10.1080/17290376.2018.1529612

[18] Gourlay, A., Wringe, A., Todd, J., Cawley, C., Michael, D., Machemba, R., Reniers, G., Urassa, M. and Zaba, B. (2015) Factors Associated with Uptake of Services to Prevent Mother-to-Child Transmission of HIV in a Community Cohort in Rural Tanzania. Sexually Transmitted Infections, 91, 520-527. 
https://doi.org/10.1136/sextrans-2014-051907

[19] Nsom Mbo, D.S. (2007) Les déterminants de la pratique du test de dépistage du VIH/Sida chez la femme enceinte au Cameroun. Mémoire DESSD, IFORD Cameroun, 111.

[20] Lubogo, D., Bosco Ddamulira, J., Tweheyo, R. and Wamani, R. (2015) Factors Associated with Access to HIV Care Services in Eastern Uganda: The Kumi Home Based HIV Counseling and Testing Program Experience. BMC Family Practice, 16, 162-169. http://www.biomedcentral.com/1471-2296/16/1/

https://doi.org/10.1186/s12875-015-0379-6 